\title{
Effect of memantine combined with citalopram on cognition of BPSD and moderate Alzheimer's disease: A clinical trial
}

\author{
TIANTIAN ZHOU* ${ }^{*}$ JINDONG WANG ${ }^{*}$, CUIYU XIN, LINGLI KONG and CHUNXIA WANG \\ Department of Geriatric Psychiatry, Qingdao Mental Health Center, Qingdao, Shandong 266034, P.R. China
}

Received May 22, 2018; Accepted December 4, 2018

DOI: $10.3892 /$ etm.2018.7124

\begin{abstract}
Among Alzheimer's disease (AD) patients, it is very common to develop behavioral and psychological symptoms of dementia (BPSD), which has a close relation to the excess morbidity and mortality, greater healthcare use, earlier institutionalization, and caregiver burden. With evaluation of AD patients, the present study mainly aims to investigate whether citalopram would be efficient for BPSD, and examines citalopram's effects on cognitive function, caregiver distress, safety and tolerability. Eighty patients diagnosed with moderate AD and clinically significant BPSD from April 2015 to January 2016 were enrolled in this study. Patients randomly received memantine plus either citalopram $(n=40$, study group) or placebo ( $n=40$, control group) in a 12 -week period. The target dose of memantine was $20 \mathrm{mg} /$ day. The dose of citalopram was $10 \mathrm{mg} /$ day in the beginning with planned titration to $30 \mathrm{mg} /$ day over 2 weeks on the basis of response and tolerability. Blood routine, urine routine, biochemical tests, electrocardiogram and electroencephalogram were carried out for each patient every month routinely to check the change induced by using medication. Treatment Emergent Symptom Scale (TESS) was used to measure untoward effects every 2 weeks. All of the agitation/aggression, irritability/lability, night-time behavioral disturbances, caregiver distress and Neuropsychiatric Inventory (NPI) total scores after treatment were found to be dramatically lower than those before treatment in both groups. Apathy, dysphoria and anxiety received lower scores in participants who received memantine combined with citalopram, compared to those before treatment. QTc interval prolongation was observed in 2 patients who were treated with $30 \mathrm{mg} /$ day citalopramin. In conclusion, memantine combined
\end{abstract}

Correspondence to: Ms. Chunxia Wang or Ms. Lingli Kong, Department of Geriatric Psychiatry, Qingdao Mental Health Center, 299 Nanjing Road, Qingdao, Shandong 266034, P.R. China

E-mail:wrj5wc@163.com

E-mail: konglingli1@sina.com

${ }^{*}$ Contributed equally

Key words: memantine, citalopram, cognitive, BPSD, caregiver distress, Alzheimer's disease, randomized trial with citalopram can more effectively improve the cognitive function, and reduce behavioral and psychological symptoms in patients with moderate AD. Cardiac adverse effects of citalopram are not common when the dose is $<30 \mathrm{mg} /$ day, which does not limit its practical application. Thus, citalopram has shown potential efficacy in adjunctive therapy of AD patients with BPSD.

\section{Introduction}

As the most common neurodegenerative disease, Alzheimer's disease $(A D)$ has the characteristics of gradual learning and memory process loss, as well as spatial abilities, confusion and altered disorientation. The etiology of AD has been assumed to be neurodegeneration as amyloid precursor protein (APP), in the form of abnormal process, makes peptide $\mathrm{A}$ to be produced, aggregated and deposited. It is marked by the senile plaque formation and the death of neuronals (1).

The non-cognitive symptoms, behavioral and psychological symptoms of dementia (BPSD) are usually related to AD, with perception, thought content, mood, and behavior disorders included. According to a study, 70-90\% of patients with dementia in the progression of the disease will appear to have BPSD within a certain period of time (2), which contributes the most to hospitalization and life quality deterioration for patients with AD, and seriously increases family and caregiver burden $(3,4)$. Results from South Korea have pointed out that caregivers' psychological distress mainly comes from BPSD when they are taking care of patients with dementia, and for the registered nurses and care workers, the most frequent distressing symptom is agitation/aggression. This indicates that it is necessary to assist mitigate caregivers' burden by improving BPSD treatments (5).

In recent years, many studies have focused on identifying treatments for BPSD $(6,7)$. Non-pharmacological interventions should come first, and then the medication, but unfortunately, pharmacological interventions need to be combined for most patients with AD. It is very challenging to treat BPSD due to the severe adverse events in dementia patients, which along with the pharmacological interventions cause limitation of time and quantity. Also, this may put patients at risk due to the shortage of licensed drugs used to treat these symptoms, as well as other optional drugs.

As a moderate-affinity uncompetitive antagonist of $\mathrm{N}$-methyl-D-aspartate (NMDA) receptor, memantine is the 
first non-cholinergic agent allowed for the treatment of AD in the USA and Europe, and is also the first medication approved to treat the disease from moderate to severe stages. Although it has been proven that memantine is efficient and safe in the treatment of dementia $(8,9)$, it can only slow down the disease process and has also certain defects in controlling BPSD, especially in the initial stage of treatment.

Antipsychotics have been used to treat AD patients' psychosis, aggression and agitation for a long time, but little progress has been shown due to adverse effects. The new atypical antipsychotics are considered effective medicines that cause fewer adverse effects. The use of atypical antipsychotics, as evaluated by clinical trials, has produced various results without clarity. Many studies have shown that atypical antipsychotics such as risperidone, olanzapine and quetiapine are significant in the treatment of behavioral disturbances and are well tolerated $(10,11)$. Studies have indicated that, despite the concerns about safety, risperidone is still been taken as a popular therapeutic choice among AD patients with psychosis (12-14). On the contrary, there are many studies indicating that olanzapine, quetiapine, or risperidone do not differ from placebo for treating BPSD (15-17). USA Food and Drug Administration (FDA) does not allow the use of atypical antipsychotics among the elderly with dementia due to the increased risk of death and serious cardiovascular events in this age group. In fact, because there is no alternative medicine, atypical antipsychotics are still used as first-line therapy for BPSD due to their favorable effect profile.

Serotonergic dysfunction has a connection with the agitation of AD patients and early clinical trial findings have shown that a suitable approach for this is SSRIs (18-20). Currently there are many studies on antidepressants from the perspective of treatment for agitation and psychosis in dementia (21-25). A meta-study has shown that compared with placebo, typical and atypical antipsychotics there is a relation between the SSRIs sertraline and citalopram, and the reduction in the symptoms of agitation, which appears to be reasonably well-tolerated compared to placebo and SSRIs. Citalopram as a typical representative of SSRIs is more practical because of its high ability of 5-HT re-uptake, low affinity to the receptors for acetylcholine, histamine, norepinephrine, no accumulation after long-term treatment and a small effect on the cytochrome P450 enzyme system. In a recent study, citalopram in Alzheimer's Disease (CitAD), was shown to have a positive effect on the treatment of AD agitation (22-25).

Our study assessed the effect, safety and tolerability of memantine combined with citalopram in patients with moderate AD with BPSD. The efficacy of memantine combined with citalopram on all BPSD, rather than agitation, was also evaluated. At the same time, we also examined the effects of memantine combined with citalopram on cognitive function and caregiver distress.

\section{Patients and methods}

Subjects. Participants were selected from both the Outpatient and Inpatient Departments of Qingdao Mental Health Center (Qingdao, China) between April 2015 and January 2016. Eighty AD patients with BPSD were enrolled. According to the AD baseline made by the 5th edition of the Diagnostic and
Statistical Manual of Mental Disorders (DSM-V), all subjects enrolled met the criteria. Each patient had a CDR score of 2, and each AD patient had at least one behavioral and psychological symptom, whose diagnosis was provided by psychiatrists. Patients were excluded under the following circumstances: age $>80$ years; development of dementia in other forms such as vascular, frontotemporal, and Lewy body; receive of acetylcholinesterase inhibitor including donepezil, huperzine, rivastigmine, or antipsychotic drugs; patients with severe heart disease, arrhythmia, especially QT interval prolongation; and patients with moderate or severe renal failure.

Two groups were established among eligible patients at random. In one group, patients were treated with memantine combined with citalopram, while in the other group, patients were treated wth memantine combined with placebo. The target dose of memantine was $20 \mathrm{mg}$ /day in both groups. The dose of citalopram was designed as $30 \mathrm{mg} /$ day and a single dose was provided in the morning. A dose of $10 \mathrm{mg} /$ day in the beginning was titrated up to $30 \mathrm{mg} /$ day over 2 weeks, and then it could be decreased to $10-20 \mathrm{mg} /$ day depending on tolerability.

The study was approved by the Ethics Committee of Qingdao Mental Health Center and implemented by the guidance of the Declaration of Helsinki. The patients and/or guardians signed an informed consent.

\section{Assessment}

Cognitive assessment. With a rating scale consisting of 11 questions and a total score of 30 points, Mini-Mental State Examination (MMSE) scoring system was applied to assess the severity of cognitive impairment. Dementia patients were distinguished from healthy subjects by three cut-off values. Scores $<17$ points were rated as illiteracte; scores $>20$ points were rated as primary school; while scores $>24$ points were rated as more than high school.

BPSD assessment. The Neuropsychiatric Inventory (NPI) was employed to assess BPSD. NPI is most widely used in the assessment of dementia-related behavioral symptoms. It is able to examine behavioral functioning in 12 sub-domains which include delusions, hallucinations, agitation/aggression, dysphoria, anxiety, euphoria, apathy, disinhibition, irritability/lability, aberrant motor activity, night-time behavioral disturbances as well as appetite and eating abnormalities $(26,27)$. NPI was administered to the caregivers of dementia patients and screening questions were asked about each sub-domain. Every caregiver was only asked of all the questions related to the domain in which the patient showed particular problems. The scores were rated on the basis of the frequency of the symptoms on a 4-point scale, a 3-point scale for the severity, and a 5-point scale for the distress caused by the symptoms.

Safety and tolerability assessment. Blood routine, urine routine, biochemical tests, electrocardiogram and electroencephalogram were done for each patient every month routinely to check the change induced by using medication. Treatment Emergent Symptom Scale (TESS) was used to assess side-effects every 2 weeks.

TESS was developed by NIMH in the United States (1973). It includes not only common adverse symptoms and signs, but also a number of laboratory test results. The advantage of this scale is that the symptoms of each system can be fully identified. 
Statistical analysis. The data entries and subsequent analyses were based on SPSS 18.0 (SPSS, Inc., Chicago, IL, USA). t-test and appropriate Chi-square test were applied for the statistical analysis. $\mathrm{P}<0.05$ was considered to indicate a statistically significant difference.

\section{Results}

General information. Table I shows demographic, clinical characteristics and assessment results of the patients in the two groups. Distinct differences did not exist concerning sex, age, and education background ( $\mathrm{P}>0.05)$; neither concerning the MMSE and NPI scores between the two groups at baseline $(\mathrm{P}>0.05)$.

Comparison of the change of MMSE and NPI scores. Marked differences existed in the change of MMSE scores between the two groups after treatment $(\mathrm{t}=3.026, \mathrm{P}<0.05)$. Patients who received memantine combined with citalopram improved dramatically in the aspect of cognitive function, in comparison to those who received memantine with placebo.

The scores of agitation/aggression, irritability/lability, behavioral disturbances overnight, caregiver distress and NPI total score after treatment decreased quickly compared to those before treatment in both groups $(\mathrm{P}<0.05)$. The scores of apathy, dysphoria, anxiety were far less than those before treatment in patients who received memantine combined with citalopram $(\mathrm{P}<0.05)$. Patients who received memantine combined with citalopram showed statistically significant reduction of total NPI, agitation/aggression, apathy, dysphoria, anxiety and caregiver distress scores compared with those who received memantine with placebo $(\mathrm{P}<0.05)$. Obvious distinction was not found in the change of the scores of delusions, hallucinations, euphoria, disinhibitions, irritability/lability, aberrant motor activity, behavioral disturbances overnight, as well as appetite and eating abnormalities $(\mathrm{P}>0.05)$ (Table II).

Comparison of the adverse events. The adverse events that most frequently appeared in the study were headache (7.5 vs. $10 \%$ ), nausea (5 vs. $10 \%$ ), dizziness (5 vs. $7.5 \%$ ) and fatigue ( 2.5 vs. $5 \%$ ) (Table III). In addition, there were 2 patients who complained of dry mouth in the study group and there was 1 patient that showed increased libido in the control group and withdrew from the study. QTc interval prolongation was observed in 2 patients who were treated with $30 \mathrm{mg} /$ day citalopram, one of whom withdrew from the study. The two groups had a similar discontinuation caused by adverse events.

\section{Discussion}

As a non-cholinergic agent, memantine is the earliest approved for the treatment of moderate to severe AD. The results of recent studies have shown that citalopram affects the treatment of agitation in patients with AD (22-25). Based on the above research, this study aimed to evaluate the potential of memantine combined with citalopram to ameliorate BPSD and improve cognitive function. It is a clinical trial developed on two parallel treatment groups characterized as randomized, double-masked, placebo-controlled, and is designed according to the advice given by the CitAD Research Group (28). A
Table I. Demographic, clinical features and assessment results of patients $(\mathrm{n}$, mean $\pm \mathrm{SD})$.

\begin{tabular}{|c|c|c|c|}
\hline Variables & $\begin{array}{l}\text { Study } \\
\text { group }\end{array}$ & $\begin{array}{l}\text { Control } \\
\text { group }\end{array}$ & P-value \\
\hline Sample size (n) & 40 & 40 & \\
\hline Sex (males/females) & $16 / 24$ & $17 / 23$ & 0.820 \\
\hline Age (years) & $71.00 \pm 3.479$ & $71.10 \pm 3.720$ & 0.901 \\
\hline Education (years) & $6.10 \pm 3.967$ & $6.45 \pm 4.032$ & 0.697 \\
\hline MMSE score & $15.10 \pm 1.945$ & $14.80 \pm 1.964$ & 0.494 \\
\hline \multicolumn{4}{|l|}{ NPI score } \\
\hline Total score & $34.92 \pm 10.388$ & $34.38 \pm 8.755$ & 0.799 \\
\hline Delusions subscore & $5.83 \pm 2.806$ & $6.00 \pm 2.160$ & 0.713 \\
\hline Hallucinations score & $0.43 \pm 1.130$ & $0.40 \pm 1.277$ & 0.926 \\
\hline $\begin{array}{l}\text { Agitation/aggression } \\
\text { subscore }\end{array}$ & $6.78 \pm 1.888$ & $6.68 \pm 2.141$ & 0.825 \\
\hline Dysphoria subscore & $3.88 \pm 2.102$ & $3.78 \pm 2.281$ & 0.839 \\
\hline Anxiety subscore & $3.83 \pm 2.395$ & $3.28 \pm 2.309$ & 0.299 \\
\hline Euphoria subscore & $1.05 \pm 2.396$ & $0.90 \pm 2.205$ & 0.772 \\
\hline Apathy subscore & $3.33 \pm 2.165$ & $3.40 \pm 2.447$ & 0.885 \\
\hline Disinhibition subscore & $1.02 \pm 2.391$ & $1.15 \pm 2.507$ & 0.820 \\
\hline Irritability/lability & $4.13 \pm 2.719$ & $5.08 \pm 2.596$ & 0.114 \\
\hline $\begin{array}{l}\text { Aberrant motor activity } \\
\text { subscore }\end{array}$ & $1.55 \pm 2.375$ & $1.27 \pm 2.375$ & 0.606 \\
\hline $\begin{array}{l}\text { Night-time behavioral } \\
\text { disturbance subscore }\end{array}$ & $1.50 \pm 2.810$ & $1.45 \pm 2.631$ & 0.935 \\
\hline $\begin{array}{l}\text { Appetite and eating } \\
\text { abnormalities subscore }\end{array}$ & $1.63 \pm 2.826$ & $1.15 \pm 2.381$ & 0.419 \\
\hline $\begin{array}{l}\text { Caregiver distress } \\
\text { total score }\end{array}$ & $16.10 \pm 4.313$ & $14.88 \pm 3.596$ & 0.172 \\
\hline
\end{tabular}

MMSE, Mini-Mental State Examination; NPI, Neuropsychiatric Inventory.

previous study had found that there should be at least a duration of 9 weeks to assure enough time for full response in the treatment with citalopram for agitation in AD (29). Since it is important for the clinical trials to have sufficient time, we evaluated the efficacy on cognition and BPSD after 12 weeks.

The first important finding was that there was a significant decrease in the scores of agitation/aggression, irritability/lability, night-time behavioral disturbances, caregiver distress and NPI total score after treatment in the two groups. This result suggests that memantine alone or memantine combined with citalopram can improve agitation/aggression, irritability/lability and night-time behavioral disturbances and reduce caregiver distress.

The results also showed that apathy, dysphoria and anxiety had scores much lower than those before treatment among patients who received memantine combined with citalopram. Citalopram as an antidepressant, can improve depression, dysphoria and anxiety. To our surprise, the results also suggested that citalopram could improve apathy.

A previous study showed that AD patients with severe apathy restarted to eat and increased their intake of fluid after 
Table II. Change of MMSE and NPI score after treatment ( $n$, mean \pm SD).

\begin{tabular}{|c|c|c|c|}
\hline Variables & Study group & Control group & P-value \\
\hline Sample size (n) & 39 & 39 & \\
\hline \multicolumn{4}{|l|}{ MMSE score at 12 weeks } \\
\hline MMSE score & $15.77 \pm 1.898$ & $14.95 \pm 2.102$ & \\
\hline Change of MMSE score & $0.67 \pm 0.772^{\mathrm{a}}$ & $0.18 \pm 0.644$ & $0.003^{\mathrm{a}}$ \\
\hline \multicolumn{4}{|l|}{ NPI score at 12 weeks } \\
\hline NPI total score & $28.00 \pm 9.995$ & $31.23 \pm 7.005$ & \\
\hline Change of NPI total score & $6.95 \pm 3.000^{\mathrm{a}}$ & $3.38 \pm 2.278^{\mathrm{a}}$ & $<0.001^{\mathrm{a}}$ \\
\hline Delusions subscore & $5.69 \pm 1.749$ & $5.77 \pm 1.980$ & \\
\hline Change of delusions subscore & $0.08 \pm 0.270$ & $0.05 \pm 0.223$ & 0.649 \\
\hline Hallucinations score & $0.36 \pm 0.986$ & $0.31 \pm 0.950$ & \\
\hline Change of hallucinations score & $0.08 \pm 0.354$ & $0.10 \pm 0.447$ & 0.780 \\
\hline Agitation/aggression subscore & $4.03 \pm 1.460$ & $4.67 \pm 1.782$ & \\
\hline Change of agitation/aggression subscore & $2.77 \pm 1.224^{\mathrm{a}}$ & $2.03 \pm 0.959^{\mathrm{a}}$ & $0.004^{\mathrm{a}}$ \\
\hline Dysphoria subscore & $2.64 \pm 1.739$ & $3.49 \pm 2.304$ & \\
\hline Change of dysphoria subscore & $1.18 \pm 0.997^{\mathrm{a}}$ & $0.13 \pm 0.409$ & $<0.001^{\mathrm{a}}$ \\
\hline Anxiety subscore & $2.44 \pm 1.759$ & $3.28 \pm 2.339$ & \\
\hline Change of anxiety subscore & $1.33 \pm 1.177^{\mathrm{a}}$ & $0.08 \pm 0.270$ & $<0.001^{\mathrm{a}}$ \\
\hline Euphoria subscore & $1.03 \pm 2.334$ & $0.85 \pm 2.084$ & \\
\hline Change of euphoria subscore & $0.05 \pm 0.320$ & $0.08 \pm 0.354$ & 0.738 \\
\hline Apathy subscore & $2.79 \pm 2.041$ & $3.36 \pm 2.401$ & \\
\hline Change of apathy subscore & $0.62 \pm 0.877^{\mathrm{a}}$ & $0.13 \pm 0.409$ & $0.002^{\mathrm{a}}$ \\
\hline Disinhibition subscore & $0.87 \pm 2.041$ & $1.03 \pm 2.194$ & \\
\hline Change of disinhibition subscore & $0.18 \pm 0.556$ & $0.15 \pm 0.489$ & 0.829 \\
\hline Irritability/lability subscore & $3.90 \pm 2.624$ & $4.77 \pm 2.311$ & \\
\hline Change of irritability/lability subscore & $0.23 \pm 0.583^{\mathrm{a}}$ & $0.28 \pm 0.724^{\mathrm{a}}$ & 0.731 \\
\hline Aberrant motor activity subscore & $1.38 \pm 2.208$ & $1.23 \pm 2.230$ & \\
\hline Change of aberrant motor activity subscore & $0.10 \pm 0.447$ & $0.08 \pm 0.354$ & 0.780 \\
\hline Night-time behavioral disturbance subscore & $1.28 \pm 2.449$ & $1.26 \pm 2.268$ & \\
\hline Change of night-time behavioral disturbance subscore & $0.26 \pm 0.637^{\mathrm{a}}$ & $0.23 \pm 0.583^{\mathrm{a}}$ & 0.853 \\
\hline Appetite and eating abnormalities subscore & $1.59 \pm 2.721$ & $1.13 \pm 2.319$ & \\
\hline Change of appetite and eating abnormalities subscore & $0.08 \pm 0.354$ & $0.05 \pm 0.320$ & 0.738 \\
\hline Caregiver distress total score & $12.85 \pm 4.209$ & $13.62 \pm 3.209$ & \\
\hline Change of caregiver distress total score & $3.18 \pm 1.571^{\mathrm{a}}$ & $1.59 \pm 1.352^{\mathrm{a}}$ & $<0.001^{\mathrm{a}}$ \\
\hline
\end{tabular}

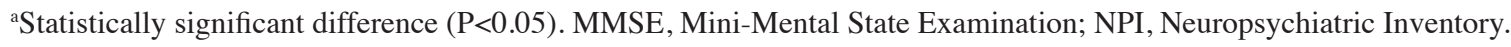

intravenous citalopram, which also supported a certain degree of efficacy of citalopram for apathy (30). Moreover, the results revealed that there was a significant difference of the score changes of agitation/aggression before and after treatment between the two groups, which suggested that memantine combined with citalopram can more effectively improve agitation/aggression. Agitation was related to low serotonin (5-HT) and many clinical studies have shown that citalopram can effectively improve agitation (22-25). Our result was similar to previous studies. In addition, the latest studies have indicated that serotonin signaling has a positive effect on $\beta$-amyloid burden and citalopram can reduce AD plaque, the major component of $\beta$-amyloid formation, which might be the reason why citalopram can reduce agitation (31-34). Comprehensive results from NPI showed that memantine combined with citalopram
Table III. Number of adverse events in the study and control group.

\begin{tabular}{lccc}
\hline $\begin{array}{l}\text { Adverse } \\
\text { event }\end{array}$ & $\begin{array}{c}\text { Study group } \\
\mathrm{n}(\%)\end{array}$ & $\begin{array}{c}\text { Control group } \\
\mathrm{n}(\%)\end{array}$ & P-value \\
\hline Headache & $3(7.5)$ & $4(10)$ & 0.692 \\
Nausea & $2(5)$ & $4(10)$ & 0.396 \\
Dizziness & $2(5)$ & $3(7.5)$ & 0.644 \\
Fatigue & $1(2.5)$ & $2(5)$ & 0.556 \\
\hline
\end{tabular}

treatment lead to a reduction of total NPI, agitation, apathy, dysphoria, anxiety and caregiver distress scores in AD patients. 
In this study, AD patients who received memantine combined with citalopram showed a distinct improvement of cognitive function in comparison to those who received memantine with placebo, which was different from previous research results. Previous researches have found that MMSE results indicate greater cognitive decline with citalopram $(22,24)$. The reasons for the compatability of citalopram to improve the cognitive function may include the following aspects. First, animal experiments have found that the use of SSRI drugs could promote the regeneration of hippocampal nerve to improve memory function (35). Second, evidence has shown that citalopram could reduce $\beta$-amyloid formation which could cause rapid disrupting of synaptic plasticity and memory impairment (31-34,36). Third, antidepressant-induced increase in BDNF levels could reduce neurotoxicity $(35,37,38)$. Fourth, antidepressant could protect tau from hyperphosphorylation $(39,40)$. Moreover, SSRI can inhibit the expression of mRNA in some inflammatory factors to reduce $\beta$-amyloid formation (41). Furthermore, we observed in the course of the study that the improvement of depression and anxiety could also assist with the improvement of the cognitive function.

Citalopram is tolerated quite well, and has been considered to be unlikely to cause drug-drug interactions and anti-adrenergic and anti-cholinergic effects, making it popular among elderly patients. However, there is evidence of QT prolongation and arrhythmia with citalopram from previous research $(22,42,43)$. QTc interval prolongations were observed in two participants who were treated by $30 \mathrm{mg}$ citalopram each day in this study. This result is in accordance with the advisory given by USA FDA and citalopram's current prescribing information. For patients $>60$ years of age, a maximum daily dose of $20 \mathrm{mg}$ of citalopram was provided by current prescribing information taking the substantially higher exposures, decreased clearance, and prolonged cardiac repolarization potential into consideration. The efficacy and adverse reaction of different doses of citalopram could not be analyzed thoroughly due to the limited number of patients. QTc interval prolongation carries clinical concern and more attention should be paid when prescribing citalopram for the elderly.

Limitations in this study can be summarized as follows: i) the number of samples was relatively small; ii) this was not a multicenter study; iii) the effect of memantine combined with citalopram on BPSD in non-Alzheimer disease forms of dementia has not been clarified; iv) the effects of different doses of citalopram on cognitive and BPSD were not analyzed; v) more comprehensive assessment of cognitive function has not been used in the study. We will design further studies considering these limitations to fully determine the efficacy, safety and tolerability of memantine combined with citalopram.

The outcomes of this clinical trial support that memantine combined with citalopram can more effectively improve cognitive function, reduce behavioral and psychological symptoms, especially agitation, apathy, dysphoria, as well as anxiety and caregiver distress in patients who have moderate AD. Cardiac adverse effects of citalopram are not common when the dose is $<30 \mathrm{mg} /$ day, which does not limit its practical application. Thus, citalopram has shown potential efficacy in adjunctive therapy of AD patients with BPSD.

\section{Acknowledgements}

Not applicable.

\section{Funding}

The study was sponsored by the Medical Research Plan of Qingdao Municipal Health Bureau (no. 2014-WJZD147).

\section{Availability of data and materials}

The datasets used and/or analyzed during this study are available from the corresponding author on reasonable request.

\section{Authors' contributions}

TZ and JW conceived and designed the study. TZ, CX, LK and $\mathrm{CW}$ were responsible for the data collection and analysis. JW and $\mathrm{CW}$ were responsible for interpreting the data and drafting the manuscript. LK and CW revised the manuscript critically for important intellectual content. The final version was read and approved by all the authors.

\section{Ethics approval and consent to participate}

The study was approved by the Ethics Committee of Qingdao Mental Health Center (Qingdao, China). The patients and/or guardians signed an informed consent.

\section{Patient consent for publication}

Not applicable.

\section{Competing interests}

The authors declare that they have no competing interests.

\section{References}

1. Kam TI, Gwon Y and Jung YK: Amyloid beta receptors responsible for neurotoxicity and cellular defects in Alzheimer's disease. Cell Mol Life Sci 71: 4803-4813, 2014.

2. Yoon PS, Ooi CH and How $\mathrm{CH}$ : Approach to the forgetful patient. Singapore Med J 59: 121-125, 2018.

3. Zheng Z, Wang J, Yi L, Yu H, Kong L, Cui W, Chen H and Wang C: Correlation between behavioural and psychological symptoms of Alzheimer type dementia and plasma homocysteine concentration. BioMed Res Int 2014: 383494, 2014.

4. Haibo X, Shifu X, Pin NT, Chao C, Guorong M, Xuejue L, Shiming B, Wenli F, Jun L, Mingyuan Z, et al: Prevalence and severity of behavioral and psychological symptoms of dementia (BPSD) in community dwelling Chinese: Findings from the Shanghai three districts study. Aging Ment Health 17: 748-752, 2013.

5. Song JA and Oh Y: The association between the burden on formal caregivers and behavioral and psychological symptoms of dementia (BPSD) in Korean elderly in nursing homes. Arch Psychiatr Nurs 29: 346-354, 2015.

6. Savaskan E, Bopp-Kistler I, Buerge M, Fischlin R, Georgescu D, Giardini U, Hatzinger M, Hemmeter U, Justiniano I, et al: Recommendations for diagnosis and therapy of behavioral and psychological symptoms in dementia (BPSD). Praxis (Bern 1994) 103: 135-148, 2014 (In German).

7. Savaskan E: Behavioral and psychological symptoms of dementia (BPSD): How to proceed. Ther Umsch 72: 255-260, 2015 (In German). 
8. Farlow MR: Graham SM and Alva G: Memantine for the treatment of Alzheimer's disease tolerability and safety data from clinical trial. Drug Saf 31: 1577-1585, 2008.

9. Maidment ID, Fox CG, Boustani M, Rodriguez J, Brown RC and Katona CL: Efficacy of memantine on behavioral and psychological symptoms related to dementia: A systematic meta-analysis. Ann Pharmacother 42: 32-38, 2008.

10. Rocca P, Marino F, Montemagni C, Perrone D and Bogetto F: Risperidone, olanzapine and quetiapine in the treatment of behavioral and psychological symptoms in patients with Alzheimer's disease: Preliminary findings from a naturalistic, retrospective study. Psychiatry Clin Neurosci 61: 622-629, 2007.

11. De Deyn PP, Eriksson H and Svensson H; Study of 115 investigators: Tolerability of extended-release quetiapine fumarate compared with immediate-release quetiapine fumarate in older patients with Alzheimer's disease with symptoms of psychosis and/or agitation: A randomised, double-blind, parallel-group study. Int J Geriatr Psychiatry 27: 296-304, 2012.

12. McNeal KM, Meyer RP, Lukacs K, Senseney A and Mintzer J: Using risperidone for Alzheimer's dementia-associated psychosis. Expert Opin Pharmacother 9: 2537-2543, 2008.

13. Katz I, de Deyn PP, Mintzer J, Greenspan A, Zhu Y and Brodaty $\mathrm{H}$ : The efficacy and safety of risperidone in the treatment of psychosis of Alzheimer's disease and mixed dementia: A meta-analysis of 4 placebo-controlled clinical trials. Int J Geriatr Psychiatry 22: 475-484, 2007.

14. Rabinowitz J, Katz I, De Deyn PP, Greenspan A and Brodaty H: Treating behavioral and psychological symptoms in patients with psychosis of Alzheimer's disease using risperidone. Int Psychogeriatr 19: 227-240, 2007.

15. Forloni $\mathrm{G}$ and Balducci C: Alzheimer's disease, oligomers, and inflammation. J Alzheimers Dis 62: 1261-1276, 2018.

16. Morgan BP: Complement in the pathogenesis of Alzheimer's disease. Semin Immunopathol 40: 113-124, 2018.

17. Paleacu D, Barak Y, Mirecky I and Mazeh D: Quetiapine treatment for behavioural and psychological symptoms of dementia in Alzheimer's disease patients: A 6-week, double-blind, placebo-controlled study. Int J Geriatr Psychiatry 23: 393-400, 2008.

18. Garcia-Alloza M, Gil-Bea FJ,Diez-Ariza M,Chen CP, Francis PT, Lasheras B and Ramirez MJ: Cholinergic-serotonergic imbalance contributes to cognitive and behavioral symptoms in Alzheimer's disease. Neuropsychologia 43: 442-449, 2005.

19. Lai MK, Tsang SW, Francis PT, Esiri MM, Keene J, Hope T and Chen CP: Reduced serotonin 5-HT1A receptor binding in the temporal cortex correlates with aggressive behavior in Alzheimer disease. Brain Res 974: 82-87, 2003.

20. Lam LC, Tang NL, Ma SL, Zhang W and Chiu HF: 5-HT2A T102C receptor polymorphism and neuropsychiatric symptoms in Alzheimer's disease. Int J Geriatr Psychiatry 19: 523-526, 2004.

21. Farina N, Morrell L and Banerjee S: What is the therapeutic value of antidepressants in dementia? A narrative review. Int J Geriatr Psychiatry 32: 32-49, 2017

22. Porsteinsson AP, Drye LT, Pollock BG, Devanand DP, Frangakis C, Ismail Z, Marano C, Meinert CL, Mintzer JE, Munro CA, et al; CitAD Research Group: Effect of citalopram on agitation in Alzheimer disease: The CitAD randomized clinical trial. JAMA 311: 682-691, 2014.

23. Porsteinsson AP, Keltz MA and Smith JS: Role of citalopram in the treatment of agitation in Alzheimer's disease. Neurodegener Dis Manag 4: 345-349, 2014.

24. Porsteinsson AP, Smith JS, Keltz MA and Antonsdottir IM: Can antidepressant medication relieve agitation in Alzheimer's disease? Expert Rev Neurother 14: 969-971, 2014.

25. Underwood BR and Fox C: Citalopram decreases agitation in the context of Alzheimer's disease, but at doses higher than those commonly prescribed and at the expense of side effects. Evid Based Med 19: 181, 2014.

26. Cummings JL, Mega M, Gray K, Rosenberg-Thompson $\mathrm{S}$ Carusi DA and Gornbein J: The Neuropsychiatric Inventory: Comprehensive assessment of psychopathology in dementia Neurology 44: 2308-2314, 1994.
27. Otero MC and Levenson RW: Lower visual avoidance in dementia patients is associated with greater psychological distress in caregivers. Dement Geriatr Cogn Disord 43: 247-258, 2017.

28. Drye LT, Ismail Z, Porsteinsson AP, Rosenberg PB, Weintraub D, Marano C, Pelton G, Frangakis C, Rabins PV, Munro CA, et al; CitAD Research Group: Citalopram for agitation in Alzheimer's disease: Design and methods. Alzheimers Dement 8: 121-130, 2012.

29. Weintraub D, Drye LT, Porsteinsson AP, Rosenberg PB, Pollock BG, Devanand DP, Frangakis C, Ismail Z, Marano C, Meinert CL, et al; CitAD Research Group: Time to response to citalopram treatment for agitation in Alzheimer Disease. Am J Geriatr Psychiatry 23: 1127-1133, 2015

30. Hellen F, Supprian T, Salamon T and Lange-Asschenfeldt C: Resumption of food and fluid intake in Alzheimer's disease with severe apathy following intravenous citalopram. Psychiatry Clin Neurosci 66: 82, 2012

31. Cirrito JR, Disabato BM, Restivo JL, Verges DK, Goebel WD, Sathyan A, Hayreh D, D'Angelo G, Benzinger T, Yoon H, et al: Serotonin signaling is associated with lower amyloid- $\beta$ levels and plaques in transgenic mice and humans. Proc Natl Acad Sci USA 108: 14968-14973, 2011.

32. Ren QG, Gong WG, Wang YJ,Zhou QD and Zhang ZJ: Citalopram attenuates tau hyperphosphorylation and spatial memory deficit induced by social isolation rearing in middle-aged rats. J Mol Neurosci 56: 145-153, 2015.

33. Erickson MA and Banks WA: Neuroimmune axes of the blood-brain barriers and blood-brain interfaces: Bases for physiological regulation, disease states, and pharmacological interventions. Pharmacol Rev 70: 278-314, 2018.

34. Pimenova AA, Thathiah A, De Strooper B and Tesseur I: Regulation of amyloid precursor protein processing by serotonin signaling. PLoS One 9: e87014, 2014.

35. Deltheil T, Guiard BP, Cerdan J, David DJ, Tanaka KF, Repérant C, Guilloux JP, Coudoré F, Hen R and Gardier AM: Behavioral and serotonergic consequences of decreasing or increasing hippocampus brain-derived neurotrophic factor protein levels in mice. Neuropharmacology 55: 1006-1014, 2008.

36. Klyubin I, Cullen WK, Hu NW and Rowan MJ: Alzheimer's disease $A \beta$ assemblies mediating rapid disruption of synaptic plasticity and memory. Mol Brain 5: 25, 2012.

37. Wolkowitz OM, Wolf J, Shelly W, Rosser R, Burke HM, Lerner GK, Reus VI, Nelson JC, Epel ES and Mellon SH: Serum BDNF levels before treatment predict SSRI response in depression. Prog Neuropsychopharmacol Biol Psychiatry 35: 1623-1630, 2011

38. van der Meij A, Comijs HC, Dols A, Janzing JG and Oude Voshaar RC: BDNF in late-life depression: Effect of SSRI usage and interaction with childhood abuse. Psychoneuroendocrinology 43: 81-89, 2014

39. Ren QG, Wang YJ, Gong WG, Zhou QD, Xu L and Zhang ZJ: Escitalopram ameliorates forskolin-induced tau hyperphosphorylation in HEK239/tau441 cells. J Mol Neurosci 56: 500-508, 2015.

40. Wang YJ, Ren QG, Gong WG, Wu D, Tang X, Li XL, Wu FF, Bai F, $\mathrm{Xu} \mathrm{L}$ and Zhang ZJ: Escitalopram attenuates $\beta$-amyloid-induced tau hyperphosphorylation in primary hippocampal neurons through the 5-HT1A receptor mediated Akt/GSK-3 $\beta$ pathway. Oncotarget 7: 13328-13339, 2016.

41. Su F, Yi H, Xu L and Zhang Z: Fluoxetine and S-citalopram inhibit M1 activation and promote M2 activation of microglia in vitro. Neuroscience 294: 60-68, 2015.

42. Wenzel-Seifert K, Wittmann M and Haen E: QTc prolongation by psychotropic drugs and the risk of torsade de pointes. Dtsch Arztebl Int 108: 687-693, 2011.

43. Vieweg WV, Hasnain M, Howland RH, Hettema JM, Kogut C, Wood MA and Pandurangi AK: Citalopram, QTc interval prolongation, and torsade de pointes. How should we apply the recent FDA ruling? Am J Med 125: 859-868, 2012.

This work is licensed under a Creative Commons Attribution-NonCommercial-NoDerivatives 4.0 International (CC BY-NC-ND 4.0) License. 